\title{
Investigation and optimization of petroleum products transportation (gasoline) in Petroleum Products Company of Ahvaz
}

\author{
Ali Mehrabi Ph.D. ${ }^{1}$ \\ Belgheys Bavarsad Ph.D. ${ }^{2}$ \\ Azar Ehrambaf Shushtar ${ }^{3}$
}

1. Assistant professor of Management Department, Shahid Chamran University of Ahvaz, Iran

2. Associate professor of Management Department, Shahid Chamran University of Ahvaz, Iran

3. Graduate student of Industrial Engineering, Islamic Azad University, Saveh Branch, Iran

\begin{abstract}
Transportation is considered as one of fundamental and important components of oil industry in the cycle of production to consumption. It is of great importance and effective in the process of economic growth. On this basis, the aim of current study is to investigate and optimize petroleum products transportation (gasoline) in petroleum products company of Ahvaz. The statistical population of it include the section of transporting the central petroleum storage of Ahvaz, whole stations of which in Ahvaz were selected as sample volume through whole number. The current study is applied, descriptive-prescriptive and in terms of methodology, it is grounded and case study. Based on this, using the existing documents in the unit of issuing petroleum storage of Ahvaz such as the distance of stations from petroleum storage, data were gathered and calculated. After designing the mathematical model based on reducing the covered distance of vehicle development and minimum time of each path, the problem was solved through genetic algorithm in MATLAB7.6 Software. Finally, the solution of reaching optimum responses was proposed.
\end{abstract}

Keywords: optimization, transportation, petroleum products, genetic algorithm

Introduction

Iran is a developing country, facing with increasing growth of population and increasing per capita of energy consumption in various residential, commercial, industrial, agricultural sectors (National Oil Company of Iran, 2015). This is while the major source of supplying energy in Iran is based on oil products. In fact, oil industry is the major section of economy and industry based on supplying energy directly from oil and petroleum products (Kabiri, shahrokhi, Eydi and Barahimi, 2017). Moreover, continues increase of demand for energy consumption leads to increase of production which is a function of the rate pf fuel and raw material availability and timely delivery of raw materials for production. The products of refining crude oil, depending on their types and properties, are included in the production cycle and consumed. In this process, the distance between refineries to the consumers shall be covered (Shafiei, 2009). On this basis, a mechanism, known as "transportation system" has been founded in oil industry. In fact, transportation is of great importance in economic, production and service systems and occupies a significant section of Gross National Production (GNP) of any country (Amirzadeh, 2010).

However, transportation section of petroleum products has been one of the biggest sections, consuming energy, as well as the major consumer of oil products which has been growing in comparison with previous years so that annual energy consumption growth in this section has reached from 12.5 million of barrel in 1967 to 273.79 million of barrel in 2008 (21.9 times more) (National Oil Company of Iran, 2015). In practice, the requirement of fuel supply for regions with high consumption is the shorter distance between oil storages, suppliers and consumption centers. Transferring, distributing and supplying energy will be better feasible through building the storage or stations of distributing petroleum products. Yet, constructing the storages or stations charges high cost and they are of industrial and development projects (Shafiei, 2009). According to what mentioned above, the improvement and optimization of petroleum products transportation is clearly necessary. It is sought to reach the agility and optimization of transportation in the cycle of petroleum products production from discovery to consumption (Gheysari and Ghannadpour, 2008). On this basis, the case study of this paper is to optimize of petroleum products transportation (gasoline) as a subset of National Oil Refining and Distribution Company of Ahwaz Region. According to Bulletin of the National Iranian Oil Company (2015), the company was founded in 1992 after approval of separation of upstream companies of oil ministry including discovery and production of gas and oil from downstream companies such as refining, transferring oil and products, exporting, importing and distributing the oil products. Distributing petroleum products is of the most important duties of National Iranian 
Oil Company which is conducted through four ways of pipeline, railway transportation, road transportation and marine transportation. National Iranian Oil Company daily supplies more than 220 million of petroleum products, the most important one of which are gasoline, gas oil, kerosene, petrol and aircraft fuel (ATKJPF), in 37 regions and more than 225 areas and distributes in various industrial, transportation, domestic, agricultural, commercial, service sections (Mansournejad, 2015).

After being received from refinery and imported wharfs, the required petroleum products are transferred to oil storages of whole country through pipelines, railway tank wagons and road tankers and then sent for consumption. Nowadays, more than ten thousands of road tankers are working in the fleet of national Distribution Corporation which are responsible for road distribution of petroleum products (National Iranian Oil Company, 2015).

Since the huge part of transferring petroleum products of National Iranian Oil Company from storages to the final customers is done by Ground Transportation System, other models of transportation such as railway ones are not considered and the regarded vehicle in the case study of this thesis is road tanker. This tanker is one of vehicles for transporting the products in National Distribution company which takes unpacked oil to the destinations of customers or in between the storages (Kabiri, Shahrokhi, Eidi and Barahimi, 2017). Given that distributing petroleum products distribution gets a huge portion of the cost of this organization and this increase of cost directly causes the full price of required products, the case study on this paper is to propose a model for optimizing and reducing the cost of transportation costs in the system of supply chain of this company. In this study, the effective factors and methods on optimization of transportation will be studied and a model will be tried to be proposed to reduce the related cost to transportation.

\section{Methodology}

The current study is applied in terms of goal and descriptive-prescriptive in terms of methodology, it is also grounded and case study in terms of methodology. The statistical population of it include the section of transporting the central petroleum storage of Ahvaz, whole stations of which in Ahvaz were selected as sample volume through whole number. Through field study and using the existing documents, the distance of stations from petroleum storage was gathered and calculated. After designing the mathematical model based on reducing the covered distance of vehicle development and minimum time of each path, the problem was solved through genetic algorithm in MATLAB7.6 Software by a personal computer with RAM 4, CPU 2.8, HDD 250. Finally, the solution of reaching optimum responses was proposed.

\section{Results}

Given the obtained information from National Company of Distributing Petroleum Products of Ahvaz, there are 34 stations inside the city, the properties of which have been proposed in table 1 . 
Table 1- The stations of National Company of Distributing Petroleum Products of Ahvaz inside the city

\begin{tabular}{|c|c|c|c|}
\hline No. & Name of station & $\begin{array}{l}\text { The distance to } \\
\text { Ahvaz storage } \\
\text { (Kilometer) }\end{array}$ & $\begin{array}{c}\text { Nominal capacity } \\
\text { of station } \\
\text { (Liter) }\end{array}$ \\
\hline 1 & Rezaei & 30 & 120000 \\
\hline 2 & Abbas & 16 & 120000 \\
\hline 3 & Valid Saedi & 24 & 120000 \\
\hline 4 & Saedi & 15 & 90000 \\
\hline 5 & Ghaffari & 33 & 120000 \\
\hline 6 & Marashi & 20 & 135000 \\
\hline 7 & Haftkal & 119 & 90000 \\
\hline 8 & Golestan & 27 & 100000 \\
\hline 9 & Khaledi & 16 & 120000 \\
\hline 10 & Kianabad & 15 & 100000 \\
\hline 11 & Ahmadi & 20 & 100000 \\
\hline 12 & Sherkati5 & 30 & 100000 \\
\hline 13 & Sherkati3 & 25 & 130000 \\
\hline 14 & Sherkati2 & 25 & 100000 \\
\hline 15 & Nisi & 24 & 90000 \\
\hline 16 & Mousavi & 26 & 90000 \\
\hline 17 & Elhaei & 71 & 90000 \\
\hline 18 & Fajr & 21 & 100000 \\
\hline 19 & Nasr & 9 & 100000 \\
\hline 20 & Saki & 32 & 120000 \\
\hline 21 & Jalali & 21 & 100000 \\
\hline 22 & Abedi & 7 & 100000 \\
\hline 23 & Vaziri & 56 & 90000 \\
\hline 24 & Ein2 & 17 & 90000 \\
\hline 25 & Raghaviyeh & 40 & 60000 \\
\hline 26 & Besat & 24 & 100000 \\
\hline 27 & Kianshahr & 10 & 100000 \\
\hline 28 & Kabi & 13 & 120000 \\
\hline 29 & Mahyaran & 44 & 100000 \\
\hline 30 & Ghayem & 45 & 130000 \\
\hline 31 & Kabi Saheli & 13 & 100000 \\
\hline 32 & Kosaran & 13 & 120000 \\
\hline 33 & Nour & 40 & 100000 \\
\hline 34 & Jonoub & 18 & 120000 \\
\hline \multicolumn{2}{|c|}{ Total covered distance } & & \\
\hline
\end{tabular}

In the next step, to optimize the system, the distance of stations from each other shall be specified. Given the lack of data, these distances are considered randomly from 10 kilometers to 100 kilometers. Therefore, the matrix of stations' distances from each other will be shown as follows:

clc

clear all

$\mathrm{nc}=34$

$\mathrm{dcc}=$ zeros $(\mathrm{nc}, \mathrm{nc})$;

for $\mathrm{i}=1$ :nc- 1

for $\mathrm{j}=\mathrm{i}+1$ :nc

$\operatorname{dcc}(i, j)=\operatorname{ceil}(10+90 * \operatorname{rand}(1,1))$;

$\operatorname{dcc}(\mathrm{j}, \mathrm{i})=\operatorname{dcc}(\mathrm{i}, \mathrm{j})$;

end

end 
to solve the problem of optimization of routing and minimizing the total distance or total cost, the following variables are required:

$\checkmark$ The number of fuel stations

$\checkmark$ The number of groups of fuel tankers

$\checkmark$ The capacity of each group of fuel tankers (one matrix with one row and columns according to the number of vehicles)

$\checkmark$ The capacity of any fuel station (one matrix with one row and columns according to the number of stations)

$\checkmark$ The distance of stations from each other (symmetric matrix, the number of rows and columns of which is same as the number of stations)

$\checkmark$ The distance of stations from central storage (the matrix whose number of rows is same as the stations with one column)

1) The model of optimizing transportation of supply chain system of National Company of Distributing Petroleum Products of Ahvaz is as follows in which target function shows the minimum covered distance in the system.

$$
\begin{aligned}
& \text { Min } \sum_{t=1}^{n-1} d N^{t} d N^{t} i+1 \\
& \text { Subject }- \text { to }=
\end{aligned}
$$

1. $N_{1}^{\prime}, N_{2}^{\prime}, \ldots \ldots . .,\left(N_{n-1}^{\prime}, N_{n}^{\prime}\right) \in E$

2. $\sum_{i=1}^{N} m i \sum_{i=1}^{N} x i j k \leq q k \quad$ for $-k=\{1, \ldots \ldots . . . k\}$

3. $N i \in N, i=1,2$,

4. $a_{i k}, w_{i k}, t_{i j}, D_{n}, q_{k}$

\section{2) Solving the model}

\section{Solving the proposed model of case study by genetic algorithm}

Genetic algorithm uses the principles of Darwin's Natural Choice to find the optimum formula for predicting or comparing the model. Darwin says that ultimately the best ones remain.

Genetic algorithm is a programming technique which uses genetic evolution as a problem solving model. Genetic algorithm is used for the problems of searching and optimization. When the term survival struggle is used, its negative meaning usually comes to mind. Jungle law may come to mind simultaneously and stronger survival. Of course, to be more relaxed, you can think that the strongest ones have been always the winner. For example, despite of huge body and being strong, the dinosaurs withdraw survival game totally naturally while weaker creatures than them survived. Nature does not apparently choose the best ones only based the size of their body but it is better to say the nature chooses the most suitable ones not best ones (Daryabeigi, 2008).

\section{$\checkmark \quad$ Natural Choice law}

Natural Choice law argues that only some species of a population survive which are of the best properties otherwise they will gradually die. For example, assume that a particular type of people is far more intelligent than other ones. In the profoundly natural conditions, these people will develop better and have relatively higher welfare which leads to living longer and better productivity. Now if this feature (intelligence) is inherited, the number of intelligent people will be naturally more in the next generation of same population because of more births. If you continue it, you will see that our sample population will be more intelligent during consecutive generations. Therefore, a simple natural mechanism has been able to remove less smart people from population within some generations, additionally, the rate of average intelligence of population is continuously increasing. So, it is seen than using a very simple method (gradual elimination of inappropriate species and higher proliferation of optimum species), the nature has been able to always promote each generation in terms of feature. Of course, this method is not merely enough (at least about what exists in nature), the existence of mutation is also required.

In fact, the natural evolution can be summarized as follows: searching blindly+ more appropriate survival (Sadeghi, 2010).

On this basis, genetic algorithm has been used to solve routing. Genetic algorithm is the one based on artificial intelligence which has consisted of some main parts as follows: 


\section{Initial population}

Initial population is in fact a series of answers the problem (chromosomes) which have been initially entered the algorithm or can be created randomly (Jafarnejad, 2008). The number of initial population depends on the complexity and type of problem. Based on that, the number of answers which should be created and investigated in any generation in parallel, are determined (Zekerdi and Beheshtinia, 2010).

\section{Chromosome}

Chromosomes consist of some genes that each one creates a sub-route from the real route (figure 1).

\begin{tabular}{|l|l|l|l|l|l|l|l|l|l|l|l|l|l|l|l|l|l|l|l|}
\hline 1 &. &. &. &. &. & 1 &. & 1 &. &. &. &. & 1 &. &. &. &. & 1 &. \\
\hline
\end{tabular}

Figure 1- The structure of chromosome

Chromosome is a string, creating a route between the source and destination. This route can be appropriate or inappropriate and even impossible, that is the route (chromosome) may consist of some sub-routes (gene) which are not continues. For example, in a net like figure 2 , if to reach from point 2 to 4 route 1 is (first gene of the chromosome), route 2 to 8 and second route (second gene of the chromosome) the route 9 to 4 , although the beginning and ending points are correct, this route cannot be the correct one because the destination of a sub-route shall be matched with the source of next sub-route to be able to maintain the continuity in the net. Of course, in the next steps, the sequence of sub-routes has been investigated in the next steps and the non-continues routes are identified and receives less value so they will be removed in next generations and converted to the correct and logical routes.

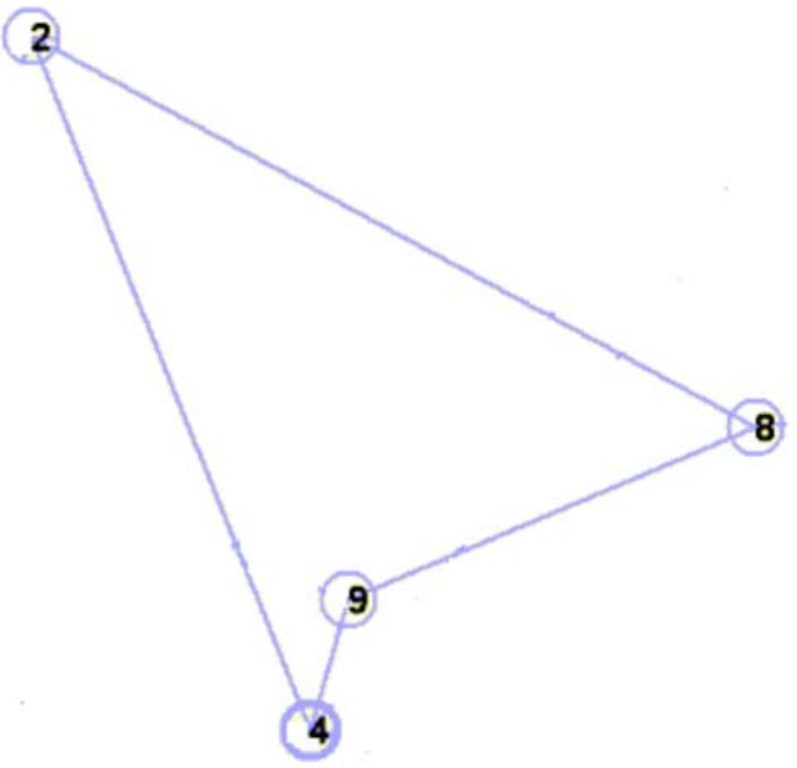

Figure 2- A part of sample net

The number of chromosome's genes depends on the type of problem. In the case of routing, since the number of sub-routes of complete route is always less than the total number of points (net nodes) minus one so for any chromosome one gene less than total existing nodes in the net has been considered. Of course, if we reach the main route with less sub-routes, the rest of genes, following chromosome, will be zero.

\section{Coding method}

Coding method depends on the type of chromosome genes, depending on the type of data for any gene, it changes (Sadeqi, 2010). For example, all genes of a chromosome can be coded in form of binary (zero and one) or a set can be defined as integers or appropriate with the range of available values for a gene. In this study, coding as integers is accepted because each one of genes indicates a sub-route with exclusive number.

\section{Selection}

In the level of selection, each one of chromosomes of initial population will be given a fitness number given the rate of appropriateness and the extent which it accords with expected conditions by the user based on defined cost function, which will be stated later. Then, based on this fitness number, indicating the rate of appropriateness of 
the intended route, sub-chromosomes will be selected through one of following methods and chosen as the parent chromosomes of next generation.

\section{1- Roulette Wheel Selection}

In this method, a relative value is considered for any chromosomes which is calculated with equation 1 and attributed to the related chromosome. In this equation, $\mathrm{f}$ is the value of chromosome fitness function. Given the obtained values according to figure 3, a sector of a single circle is allocated to any chromosome. By rotating the wheel, given the area of sectors, some chromosomes are selected and take to the next steps as the parent of next generation.

$$
\frac{f\left(x_{i}\right)}{\sum f\left(x_{i}\right)} \times 100
$$
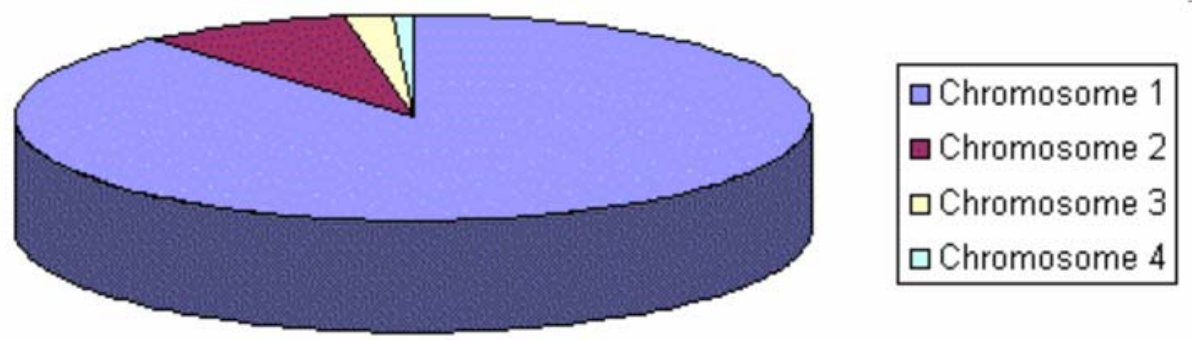

Figure 3- the structure of Roulette Wheel

\section{2- Rank selection}

In this method, the population of generation is ordered then each chromosome is given a number considering its fitness. In comparison with the previous method, the advantage of this method is that when the difference of fitness values is high in chromosomes, it acts better but because the difference of chromosomes decreases, the convergence occurs very slowly.

\section{3- Steady-state selection}

In genetic algorithm, this types refers to when in all productions, the number of good chromosomes (with high fitness) are selected to make new children and then some of bad ones (with low fitness) are removed and instead the new children are replaced and the new created generation is maintained for new production (Sadeqi, 2010).

In the simulation of this study, steady-state selection has been used because of more accordance.

\section{Displacement}

Displacement in genetic algorithm has the main role in convergence and reaching the optimum point. According to figure 4 and 5 , it is done through one of single-point displacement, dual-point displacement and multi-point displacement methods (Jafarnejad, 2008).
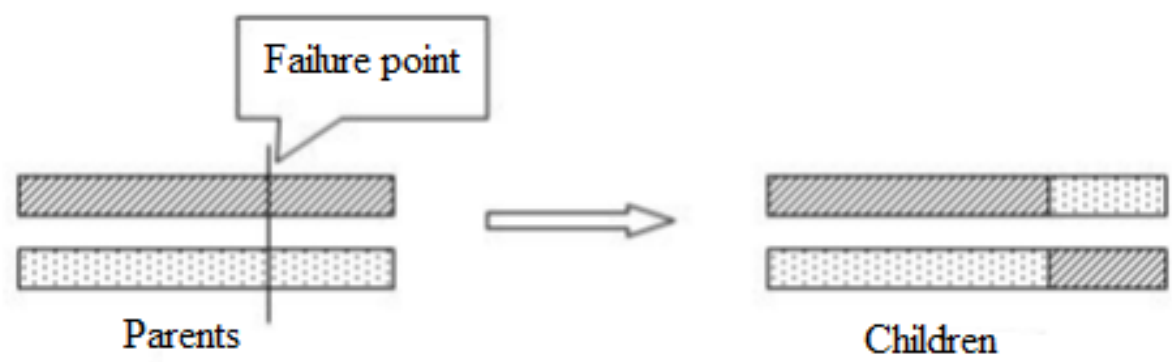

Children

Figure 4- single-point displacement 


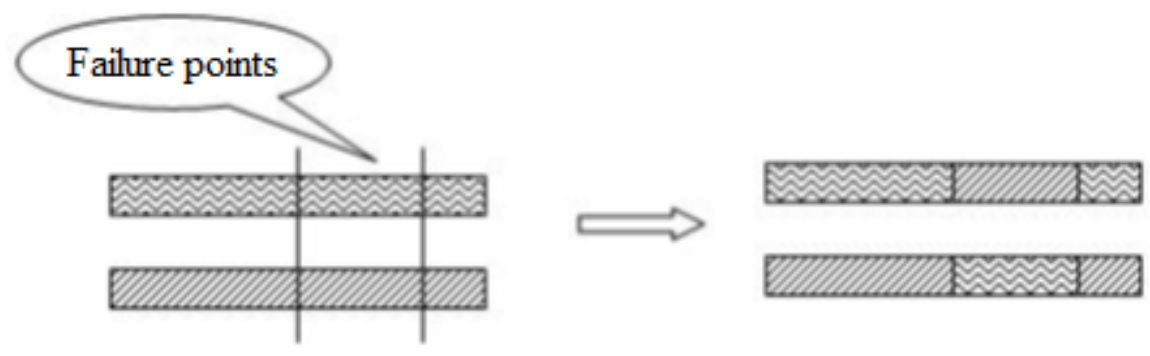

Figure 5- Dual-point displacement

In the used method of this study, the first form has been used.

\section{Mutation}

Random change in the value of a gene in any string is known as mutation. In binary alphabet, applying the mutation operator one a bite, if the value of gene is one, it will turn to zero and vice versa (figure 6) (Sadeqi, 2010).

In this study, 12 chromosomes are first considered completely optionally. Each one of them includes 34 genes, indicating a customer. The initial problem with initial data was inserted in target function without any operation and the initial answer was obtained. In other word, the first generation was created.

Two efficient operators have been designed from the type of genetic ones for surveying in possible space and obtaining neighborhood solution. They are:

1- Crossover operator: two related routes to two vehicles of current answer have been randomly selected and then two groups from two routes are changed with each other, meeting the limitations of vehicle capacity and the time of service.

2- Mutation operator: in this one, two related routes to two vehicles from current possible answer are randomly selected and then one group is eliminated from a route and added to other route, meeting the limitations of vehicle capacity and the time of service. To solve the model in one day, we consider that 34 first stations that are 1 to 34 shall be serviced.

The rate of mutation here is $2 \%$ and crossover rate is 0.5 . the number of producing the generations was considered as 350 . The first optimum answer after 50 generations is as follows:

In which, the route of optimum move of each group of fuel tankers is obtained so that the total covered distance in the system is minimized.

In these results, each number is a fuel station whose name is stated in table 1. For example, 26 indicates Best station with the distance of 24 kilometers from storage and nominal capacity of 100000 liters.

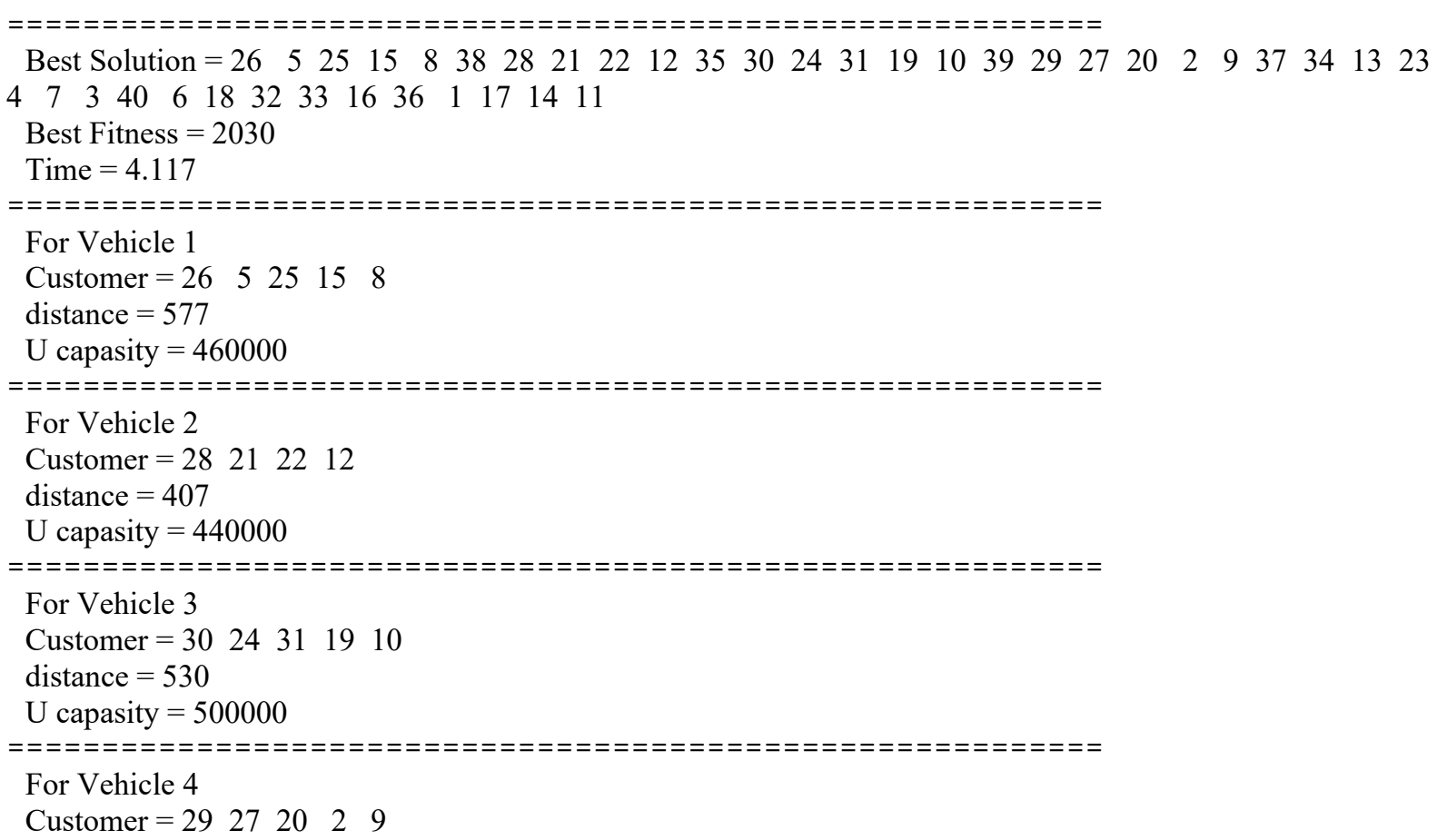



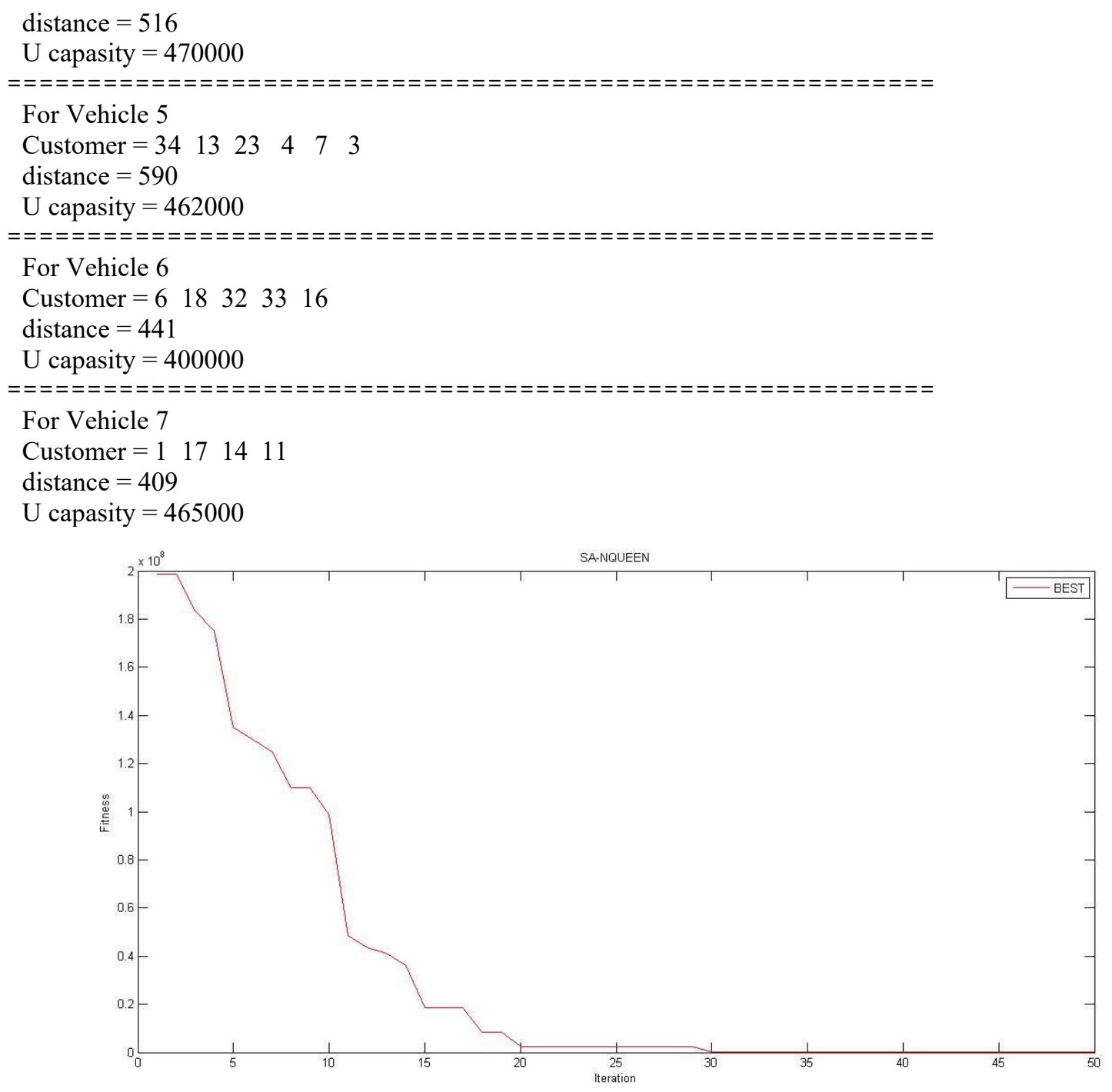

\section{4-7- The solution for operationalizing the obtained time by solving the model}

After proposing the mathematical model and its solution by genetic algorithm, real-time is introduced. One of the issues of travelling time based on transportation smart systems is the information of real time traveling time which can propose the dynamic information of changes in traveling time in the current time. Real-time is feasible using video systems or cameras and magnetic rings of Global Positioning System (GPS) and other traffic sensors on the routes of transportation network.

In a real transportation network, traffic data can be collected using the equipment of smart systems of transportation such as revealing rings on the main routes of Urban Transport Network. The most important traffic data in this study is the speed of vehicle on the routes. Since the main routes of biggest cities are equipped with revealing rings and also the distance on intersections between the nodes can be measured on a road network map, using the output of equipment of smart transportation systems, through availability of estimated light speed average, the average time of traveling on any edge or between any pair of network nodes can be calculated through the length of edge divided by speed. Therefore, due to the lack of real-time data related to traveling times, the proposed method which is one of indirect methods in measuring the times of real-time, can be used.

\section{4-8- The approach of the shortest route in transportation network}

The problems of the shortest route are often studied in the subset of flow optimization in the network. The major application of such problems in transportation or communications such is to find the route with the shortest time of distance between two nodes or pair of source-destination groups of the network. Now, the algorithms of the shortest route are introduced: 


\section{4-8-1- State Shortest Path (SSP)algorithm}

In the dynamic transportation networks, the value of data, the weights of edges, depends on the time and changes according to it. in the application of transportation especially in urban networks, in which the time of passing edges depends on the volume of traffic, because of weakness of SSP in real-time conditions, dynamic networks condition shall be used for calculating the shortest path.

\section{4-8-2- Dynamic Shortest Path (DSP) algorithm}

In the dynamic transportation networks, the value of data, the weights of edges, depends on the time and changes according to it. in the application of transportation especially in urban networks, in which the time of passing edges depends on the volume of traffic, because of weakness of SSP in real-time conditions, the dynamic conditions shall be used for finding the shortest path because calculating the time of traveling is difficult due to the accidents and damages of vehicle. To solve the model, artificial intelligence algorithms are used.

\section{4-8-2-1 uncertainties of dynamic routing problem}

Due to inadequacy of existing models, there is no effective answer for the problem of the shortest dynamic path when the value of edges dynamically changes, affected by some uncertainties such as unpredictable accidents (while the structure of network is fixed). The other point is that, due to complicated conditions of the network, there is no complete information from the changes of edges value. Therefore, due to difficulty of calculations of the DSP in traffic situation of recent vehicle damage, finding an alternative formulation for the algorithms of the route which provide good estimations of optimum answer and reduces the execution time of calculations is one of the strong motives for studies in this field. the proposed alternative formulation is to use a series of artificial intelligence methods which are smart factors.

Now, to affect transportation systems, perceiving the dynamic conditions of the environment (using revealing devices or sensors), increase the flexibility and ability of matching traveling route of vehicles with some uncertainties such as unpredictable changes in the current conditions of network such as unpredictable events: accidents, damage of vehicles, emergency repair of streets and ..., update the traffic information of decision making nodes of the network (local information) based on current conditions or real time to choose alternative paths, operating-oriented techniques can be used as one of common subjects of artificial intelligence (AI). In order to this, assume some smart factors (software or hardware system with the ability of self-control, learning and ...) which are convergent are deployed in the study nodes for controlling and local decision making and in fact the nodes of network become smart. To use previous experiences, in addition to collect and store the information of transportation, these factors also learn. Of the other important features of proposed framework are considering the communications and flow of information, transferring knowledge from one factor to another, coordination and cooperation between related factors (adjacent) or in other word using interactive or multi-factor systems for network routing.

\section{4-9- describing the flows between the components of proposed framework}

The equipped vehicle receives traffic advise and path guidance according to the following flows from each smart factor, deploying in node (or intersection) of the network.

The equipped vehicle asks for the best route for next move from the smart factor of node. To lead the vehicle, smart factor asks required traffic information from the sensors of routes. Real-time traffic information is transferred from sensors to the smart factor and it does the routing calculations through learning. To learn, it collects and stores transportation information as well as experiences of past. Smart factor propose the required traffic advise to the drivers of the vehicles for moving in next routes.

\section{4-10- practical use of the study}

Providing the required infrastructures as well as getting the required outputs from smart transportation systems, implemented to collect the information of real-time from traffic network especially relate data to the speed of vehicles are the most important steps in practical execution of this study. The other subject is that learning factors in this study using simulation models can somehow provide real traffic conditions but functionalizing the mentioned models in a real system requires intersections to be equipped with the nodes of required hardware and software networks and designing and simulating the real traffic network. 


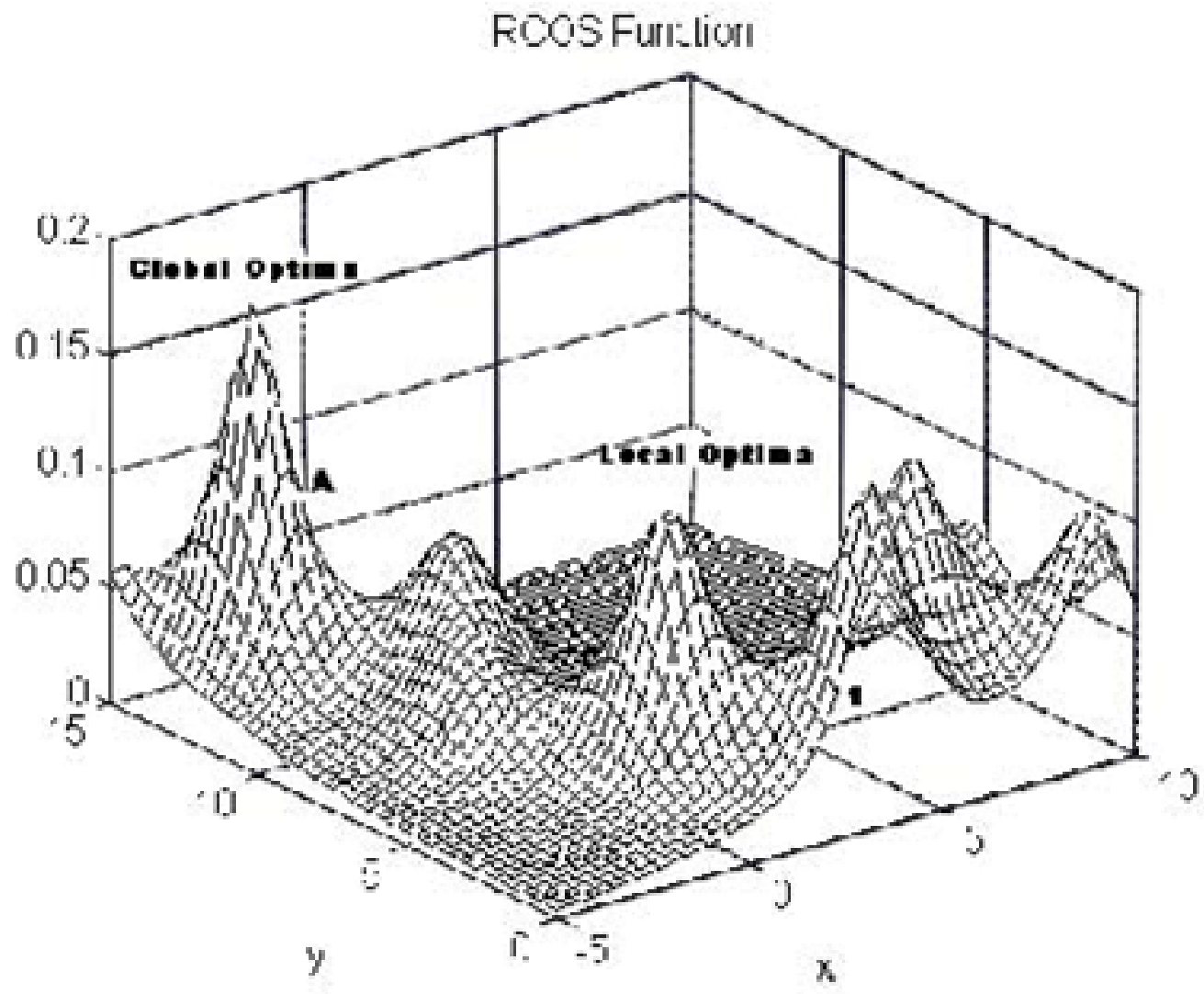

\section{Discussion}

Given the importance of supplying and distributing the required fuel of consumers in the population and increasing the per capita of energy consumption, petroleum products should be distributed faster and cheaper. Related routing is to find an ideal route, providing the model goals and following the customer while planning vehicle shall determine the time, shall be given to any customer (Kabiri, Shahrokhi, Eidi and Barahimi, 2017). Therefore, in the subject of time, total cost of route includes the cost of total distance and service times and other depending costs as well as total cost of expectations. On this basis, the current study was conducted aiming to investigate and optimize the petroleum products transportation (gasoline) in petroleum products company of Ahvaz. It led us to three main questions based on obtained findings from used mathematical model on the basis of reducing covered distance of developing vehicles and minimum time of each route through genetic algorithm. Their answers will be separately for each question:

1) How can we propose a model for optimizing transportation in the system of supply chain so that the costs of transportation as well as the costs of supply chain are reduced?

Proposing a linear planning model helps us to optimize transportation in the system of supply chain and also reach the minimum possible time. Ideal planning minimizes deviation from these two targets meanwhile it meets our intended limitations in the problem.

2) How is optimization of transportation system possible using mathematical planning?

As indicated, the parameters of model above have been obtained in the real world and replaced in mathematical model. We could both solve the model in classical way such as Sampax or Lexiconograph method and innovative methods. Yet, since classical methods merely searches limited area for optimum answer and requires a lot of time, heuristic method of genetic algorithm was used to solve this mathematical model.

3) Given that improving transportation system could be important in reducing the costs, is a mathematical planning model an ideal solution for this problem?

Since mathematics has helped human being for many years, in this case also a mathematical model has led us to the desired results with optimum answer.

Finally, despite the limitations of current study, especially because it has been done on optimization of petroleum products transportation (gasoline) in petroleum products company of Ahvaz through genetic algorithm, the obtained results of this study shall be generalized to other stations of the country more cautiously. On this basis, 
some studies about optimization of and optimize petroleum products transportation (gasoline) in other storages of the country are recommended to be conducted. Some studies are also recommended to be done using heuristic algorithms to optimize and optimize petroleum products transportation (gasoline) in petroleum products company of Ahvaz. In terms of application, the obtained results of this study are suggested to be used in decision making and planning of petroleum products company of Ahvaz management system to help better optimization petroleum products transportation (gasoline) of Ahvaz by reducing the deterrent factors.

\section{References}

[1] Jamali, Firouzabadi, Mahmoud (2014). The Effect of Storytelling on Social Skills and the Relationship of the Child with the Parents of Preschool Children, Journal Title: Psychological Research: Summer 2014, Volume 6, Number 22; From page 88 to page 97.

[2] Amirzadeh, Mahdi (2010). Presentation of a mathematical model for evaluating the 37 performance of the National Iranian Oil Refining and Distribution Company, Shiraz Islamic Azad University

[3] Jafarnejad, Ahmad (2008). Management, production and modern operations. The publications of Tehran Management Faculty

[4] Zekerdi, Sayed Hesam, Beheshtinia, Muhammad Ali (2007). Integration of transport scheduling in a chain with vehicles of different capacities of Tarbiat Modares University

[5] National Iranian Oil Company (2015). An introduction to the National Oil Company of the South. Tehran: Strategic Bureau of the Ministry of Oil of the Islamic Republic of Iran.

[6] Shafiei, Morteza (2009). Strategic Supply Chain Management, Terme Publishing

[7] Sadeqi, Hamed (2010). Setting of pid parameters using genetic algorithm in indirect control of induction motors, Azad University, Dezful Branch

[8] Gheisari, Keyvan, Ghannadpur, Sayed Farid (2008). Locomotive Routing in Network with University of Science and Technology

[9] Kabiri, Maryam; Shahrokhi, Mahmoud; Eidi, Alireza; Barahimi, Amirhossein (2017). Planning the Transportation of Multiple Petroleum Products Considering the Timeframe for Supply, Demand and Transportation (Case Study: Kurdistan Province). Journal of Engineering and Management of Sharif

[10] Mansournejad, Ebrahim (2015). He became the director of human resources in southern oil fields. Tehran: Zagrosyan. 